\title{
Identifying patients in dental settings at risk of cardiovascular disease and diabetes
}

\author{
Göran Friman ${ }^{1,2^{*}}$, Inger Wårdh', Gunnar Nilsson ${ }^{3}$ and Margareta Hultin ${ }^{4}$ \\ ${ }^{*}$ Correspondence: goran.friman@ki.se \\ 'Department of Dental Medicine/Division of Gerodontics, Karolinska Institute, Huddinge, Sweden. \\ ${ }^{2}$ Department of Health and Environmental Sciences, Karlstad University, Sweden. \\ ${ }^{3}$ Department of Neurobiology, Care Sciences and Society, Karolinska Institute, Huddinge, Sweden. \\ ${ }^{4}$ Department of Dental Medicine/Division of Periodontology, Karolinska Institute, Huddinge, Sweden.
}

\begin{abstract}
Background: The purpose of our study was to identify patients in a dental setting at risk of already having or developing high blood pressure or high plasma glucose, investigate possible associations between these conditions and periodontal status and explore the correlation between screening results and follow-up assessments concerning the need for medical treatment and/or lifestyle changes performed by medical staff.

Methods: A total of 170 dental patients were consecutively included at their regular yearly check-up visit. Data on age, weight, height, amount and use of tobacco and medication for cardiovascular disease and diabetes mellitus were collected, as well as data about systolic and diastolic blood pressure, in addition to pulse and plasma glucose. Clinical and radiographic examinations revealed data about periodontal status by probing periodontal pockets and measuring marginal alveolar bone loss by means of $\mathrm{x}$-rays. Patients who exceeded normal diastolic blood pressure and plasma glucose values were referred for diagnosis and care.

$\underline{\text { Results: }}$ Thirty-nine patients exhibiting high values were provided referrals and 24 or $14.1 \%$ of the 170 participants required additional care. The correlation between oral and medical health care concerning blood pressure recorded was $64.5 \%$ ( $<<0.001$ ), while the correlation was $40.0 \%(\mathrm{p}<0.001)$ concerning plasma glucose. Among middle aged men and elderly subjects, the data revealed/showed a significant correlation between marginal alveolar bone loss and high systolic blood pressure $(\mathrm{p}=0.001)$.

Conclusions: The correlation between oral health care and medical health care registrations based on blood pressure and plasma glucose indicates that it may be appropriate for dental professionals to perform opportunistic medical screening and refer risk patients to the medical care system before complications occur. In order to identify medical risk patients in dental settings on the basis of high blood pressure, a suggestion may be to examine middle-aged men and elderly patients of both sexes who exhibit radiographic markers for marginal alveolar bone loss.
\end{abstract}

Keywords: Blood pressure, dental settings, diabetes mellitus, elderly, medical screening, men, periodontal status

\section{Introduction}

There is a rapidly-growing elderly population in the world today, which implies a change of scenario in both oral and general health care contexts. The risk of developing both oral and general diseases increases with age. At the same time, there is only limited access to advanced treatments, both oral and general. Thus, early identification of the risk of developing diseases and early diagnosis are necessary in order to avoid exacerbating complications and extensive medical care. The epidemiological associations of periodontal disease with diabetes mellitus (DM) have been acknowledged for over a century and the association of cardiovascular disease (CVD) with periodontal disease has been recognized for just over two decades [1]. A meta-analysis, in which high blood pressure (BP) exemplified a controlled variable for CVD, indicates that the prevalence and incidence of CVD significantly increase in patients with periodontal disease [2]. In other words, the associations between oral and general health present new opportunities.

In recent years, a relationship between the treatment of periodontal disease and the prevalence of risk markers for CVD has also been recognized. For example, in a controlled case study, periodontitis has been associated with several risk markers for CVD, as well as increased levels of C-reactive protein, glucose, fibrinogen and Interleukin-18, in addition to decreased levels of Interleukin-4 [3]. Furthermore, it was discovered that the standard treatment for periodontal disease induces systemic changes in several biochemical markers that reflect a risk to develop atherosclerosis $[\mathbf{4 , 5}$.

In a study comprising a homogeneous adult population in northeast Germany, type 1 and type 2 DM were both associated with an increased prevalence and extent of periodontal disease and tooth loss as compared with non-diabetic subjects [6]. Chronic periodontitis measured by clinical attachment loss and pocket depth was also positively associated with impaired fasting glucose and diabetes in U.S. adults [7].

Another relevant issue is whether dentists are willing to incorporate chairside medical screening. Data from a selfadministered study questionnaire to 7,400 U.S.-based practicing dentists showed that these respondents were positively inclined towards integrated disease prevention [8].

These associations, combined with positive attitudes of

(c) 2013 Friman et al; licensee Herbert Publications Ltd. This is an Open Access article distributed under the terms of Creative Commons Attribution License (http://creativecommons.org/licenses/by/3.0). This permits unrestricted use, distribution, and reproduction in any medium, provided the original work is properly cited. 


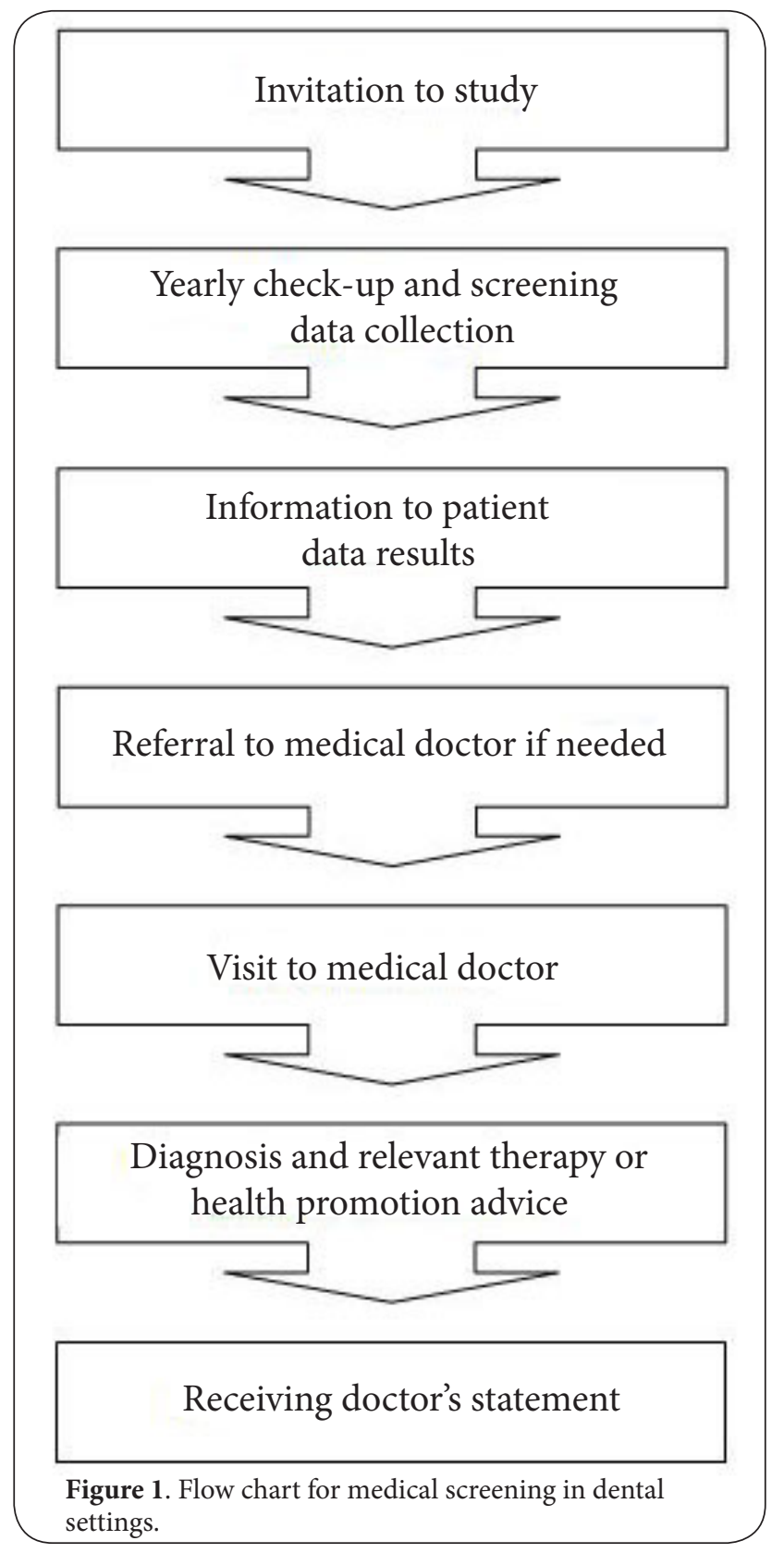

dentists make it desirable to implement medical screening for high BP [9] and DM [10] in dental settings. The purpose of our study was to identify patients in an ordinary real-world dental setting at risk of already having or developing high blood pressure or high plasma glucose, investigate possible associations between these conditions and periodontal status and explore the correlation between screening results and follow-up assessments concerning the need for medical treatment and/or lifestyle changes performed by medical staff.

\section{Methods}

The study was approved by the local Ethical Committee in Uppsala, Sweden (file 2005:358) and was conducted in agreement with the terms of the Helsinki Declaration.

\section{Setting}

This study was performed in an everyday dental setting in a small town in mid-Sweden. At the time of the study, the clinic was responsible for treating about 1,450 adult patients with a mean age of approximately 57 years ranging from 20 to approximately 100 in age. All patients were enrolled in an individualized prophylactic care program and had appointments with the dental hygienist or prophylactic dental nurse on an individual basis. In addition to the prophylactic program, an annual full-mouth dental examination was generally performed on each patient by a dentist. For a flow chart of the medical screening, see (Figure 1).

\section{Subject selection}

Two hundred seven consecutive regular patients $\geq 40$ years of age who had been recalled to their regular yearly checkup visits between March and October 2004 were invited to participate in the study. One hundred seventy patients agreed to participate. Upon receiving both verbal and written information about the study, all subjects included gave their informed consent for the study to be conducted.

\section{Study subjects were divided into two groups:}

1. Middle-aged : Patients $\geq 40-\leq 64$ years of age during the year of data collection.

2. Elderly: Patients $\geq 65$ years of age during the year of data collection.

\section{Data collection}

Data were collected through a self-administered written health declaration made before the dental appointment: age, weight, height, type and amount of tobacco use and medication to treat CVD and DM. Body mass index (BMI) was calculated and defined as an individual's body weight divided by the square of his or her height. Overweight was defined as a BMI value above 30.0 for men and above 28.6 for women.

\section{Clinical examination}

After a five-minute rest in the dentist's examination chair in the examining room, using digital BP registration [11], data about both systolic and diastolic BP and pulse were collected. The $\mathrm{BP}$ and pulse rate were measured by using a wrist device, an automatic sphygmomanometer NAIS DIAGNOSTEC EW 3002 (Matsushita Electric Works, Germany).

Plasma glucose was measured by means of a digital capillary blood sample, 3-3.5 $\mu \mathrm{L}$ using a medical device, a glucometer called Roche Accu-Chek Compact (Roche Diagnostics GmbH, Roche Diabetes Care, D-68298 Mannheim, Germany). The device was independently and objectively evaluated [12].

Data collection for plasma glucose was not predominantly performed with fasting patients, which explains why the risk values determined rather than the diagnosis, were set 
by an experienced diabetes physician, Gunilla Hede of the Diabetes Centre, Karlstad Hospital, Sweden, with respect to the time lapsed since last consumed meal. For patients who had eaten during the past two hours, the value was set at 9.5 $\mathrm{mmol} /$ litre plasma and for those who not had eaten during the past two hours, the value was established at $8.0 \mathrm{mmol} /$ litre plasma. For those fasting for the past eight hours, the cut-off value was set at $7.0 \mathrm{mmol} /$ litre plasma [13].

The cut-off values for diastolic BP was set at $90 \mathrm{~mm} \mathrm{Hg}$ or more, except for diabetics in which case the value was set at $85 \mathrm{~mm} \mathrm{Hg}$ or more, generally $140 \mathrm{~mm} \mathrm{Hg}$ or more for systolic BP. Patients who exceeded normal plasma glucose and diastolic BP values were referred to a medical doctor to have their values checked, possibly determine a diagnosis and initiate relevant therapy, or alternatively, receive health promotion advice [1].

All patients underwent clinical and radiographic examination performed by one of the clinic's two experienced and calibrated dentists who followed a detailed written protocol for data collection. These dentists have enjoyed a lengthy professional relationship, both in educational and clinical contexts, and daily discuss how to best measure and interpret clinical findings. Other categories of staff had been undergoing training specific to the medical screening project. The number of teeth was counted. Clinical periodontal status was assessed by recording bleeding on probing (BOP) and by probing the pocket depth on five predetermined teeth in each patient, tooth numbers $16,21,24,41,44$ [14] using a periodontal probe, LM 23-520B Si with a $0.5 \mathrm{~mm}$ ball diameter tip (LM-Instruments Oy, Finland).

Pocket depth was measured on six surfaces of each selected tooth (distobuccal, midbuccal, mesiobuccal, mesiolingual, midlingual, distolingual) and expressed in $\mathrm{mm}$ as the distance between the gingival margin and the base of the periodontal pocket. Recordings of pocket depth and BOP were made on four surfaces (distal, buccal, mesial and lingual) on each measured tooth, choosing the deepest site on the measured approximal surface. Only a pocket depth of $\geq 4 \mathrm{~mm}$ was recorded.

\section{Radiographic examination}

A radiographic examination [15] of the periodontal status was undertaken on dentate patients and comprised of two or four bitewing $x$-rays using a standardized long-cone parallel technique, a routine examination as part of the yearly check-up visit. No bitewing $\mathrm{x}$-rays were taken on patients with canine to canine small dentitions.

The marginal alveolar bone loss on bitewing radiographs was measured on each patient using a digital slide calliper from the cemento-enamel-junction (CEJ) to the crest of the alveolar bone on the approximal surfaces of canines, premolars and molars. A Mattson binocular with two-fold magnification was used to measure the $\mathrm{mm}$ distance from the CEJ to the alveolar bone crest. The distance was recorded
Table 1. Quartiles of clinical and radiographic periodontal status.

\begin{tabular}{lccc}
\hline Periodontal status & $\begin{array}{c}\text { Lower quartile } \\
(\mathbf{q} 1)\end{array}$ & $\begin{array}{c}\text { Between lower and } \\
\text { upper quartiles }(\mathbf{q} 2)\end{array}$ & $\begin{array}{c}\text { Upper quartile } \\
(\mathbf{q} 3)\end{array}$ \\
\hline $\begin{array}{l}\text { Number of pockets with } \\
\text { depth } \geq 4 \mathrm{~mm}\end{array}$ & 0 & $>0-<3$ & $\geq 3$ \\
$\begin{array}{l}\text { Mean depth of pockets } \\
\geq 4 \mathrm{~mm}\end{array}$ & $0 \mathrm{~mm}$ & $>0-<4.5 \mathrm{~mm}$ & $\geq 4.5 \mathrm{~mm}$ \\
$\begin{array}{l}\text { Total mm of pocket depth } \\
\geq 4 \mathrm{~mm}\end{array}$ & $0 \mathrm{~mm}$ & $>0-<15 \mathrm{~mm}$ & $\geq 15 \mathrm{~mm}$ \\
\begin{tabular}{l} 
Marginal alveolar bone loss \\
\hline
\end{tabular} & $<2 \mathrm{~mm}$ & $\geq 2-<3.4 \mathrm{~mm}$ & $\geq 3.4 \mathrm{~mm}$ \\
\hline
\end{tabular}

and rounded off to the nearest $0.1 \mathrm{~mm}$ ( 0.05 rounded up). Marginal alveolar bone loss represents the mean distance of each patient. Radiographic readings were made in a randomly selected order twice by two independent readers, authors GF and MH. If the CEJ on an approximal surface could not be detected, the CEJ on the opposite surface of the same tooth or the neighbouring tooth was used as reference. Missing data or which the CEJ or marginal bone crest was undetectable, were specified as percentages of the total number of measured surfaces.

The agreement among examiners on radiographic readings was $90 \%$ and an analysis of the correspondence of the radiographic readings between the two examiners showed that the principal investigator (GF) measured the marginal bone loss to be a mean $0.1 \mathrm{~mm}$ less than the co-author and specialist in periodontology $(\mathrm{MH})$.

Quartiles of clinical and radiographic periodontal status To evaluate variations of BP and plasma glucose in patients with varying clinical and radiographic periodontal status, partitions into quartiles were set on marginal alveolar bone loss, as well as the number and mean depth of periodontal pockets bleeding with a total registered pocket depth of $\geq$ $4 \mathrm{~mm}$. (Table 1) shows the partition into quartiles.

\section{Statistical analysis}

Statistical analyses were performed using the SPSS statistical software (Release 18.0.0 SPSS Inc., Chicago, IL). Potential correlations between periodontal status and systolic/diastolic BP were analyzed using Student's t-test, Spearman's rank correlation and Chi-Square Tests with a $p$-value $\leq 0.05$ as significance level.

\section{Results}

\section{Background data}

Of the 207 consecutively invited patients, 170 were recruited at their recalls for regular yearly check-up visits. The dropout rate was $17.9 \%$, with the main explanations for not participating "no special reason" or "have regular medical care contact". Other common reasons were "long distance for any sampling" and "do not want to know about an undiagnosed illness". Rare frequent reasons included "don't want" and "have given lab-samples elsewhere". 
Friman et al. Cardiovascular System 2013,

http://www.hoajonline.com/journals/pdf/2052-4358-1-5.pdf

doi: 10.7243/2052-4358-1-5

Table 2. General and related medical background data.

\begin{tabular}{|c|c|c|c|c|c|c|}
\hline & \multicolumn{2}{|c|}{$\begin{array}{c}\text { Total } \\
\mathrm{N}=170(100 \%)\end{array}$} & \multicolumn{2}{|c|}{$\begin{array}{l}\text { Middle-aged } \\
\mathrm{n}=90(52.9 \%)\end{array}$} & \multicolumn{2}{|c|}{$\begin{array}{c}\text { Elderly } \\
\mathrm{n}=\mathbf{8 0}(47.1 \%)\end{array}$} \\
\hline & Total & Men/ Women & Total & Men/ Women & Total & Men/ Women \\
\hline Total & 170 & $76 / 94$ & 90 & $42 / 48$ & 80 & $34 / 46$ \\
\hline$\%$ in group & - & $44.7 / 55.3$ & - & $46.7 / 53.3$ & - & $42.5 / 57.5$ \\
\hline Mean BMI & 26.3 & $26.6 / 26.1$ & 27.0 & $27.8 / 26.3$ & 25.6 & $25.1 / 25.9$ \\
\hline Smokers & 23 & $10 / 13$ & 19 & $8 / 11$ & 4 & $2 / 2$ \\
\hline$\%$ in group & 13.5 & $13.2 / 13.8$ & 21.1 & $19.0 / 22.9$ & 5.0 & $5.9 / 4.3$ \\
\hline Smoked 6 or more cigarettes/day & 17 & $6 / 11$ & 16 & $6 / 10$ & 1 & $0 / 1$ \\
\hline$\%$ in group & 10.0 & $7.9 / 11.7$ & 17.8 & $14.3 / 20.8$ & 1.3 & $0 / 2.2$ \\
\hline Medication for diabetes mellitus & 12 & $9 / 3$ & 5 & $4 / 1$ & 7 & $5 / 2$ \\
\hline$\%$ in group & 7.1 & $11.8 / 3.2$ & 5.6 & $9.5 / 2.1$ & 8.8 & $14.7 / 4.3$ \\
\hline Mean pulse rate & 69.3 & $69.1 / 69.4$ & 70.2 & $70.9 / 69.6$ & 68.3 & $67.0 / 69.2$ \\
\hline
\end{tabular}

One individual medicated for low BP

The mean age was 63.95 years (SD 12.4) ranging from 40 to 88 , with more women (94) than men (76) participating. Two patients (1.2\%) were edentulous and 31 patients (18.2\%) were overweight according to their BMI values.

\section{Plasma glucose and blood pressure}

Of the 170 participating patients, 39 were referred to a medical doctor due to high diastolic values and/or high plasma glucose levels at their screenings. Ten of these 39 patients exhibited plasma glucose values beyond the cut-off level, fasting glucose $>7.0$ millimoles per litre $(\mathrm{mmol} / \mathrm{l})$ or values in excess of levels adjusted to elapsed time since their last meals. Four of these ten required further care according to the medical physician conducting their examinations. The correlation between oral health care and medical care in recording plasma glucose was $40.0 \%(p<0.001)$.

Thirty-one of the 39 who were referred exhibited diastolic BP beyond the cut-off level at the screenings. Twenty of these 31 patients who exceeded normal diastolic blood pressure required further care according to the examining medical physician. The correlation between oral health care and medical care in recording blood pressure was $64.5 \%(p<0.001)$. Three of these 20 also required further care caused by high plasma glucose, which demonstrates the close relation between high $\mathrm{BP}$ and high plasma glucose. We found systolic BP significant correlated to plasma glucose $(p=0.005)$.

Consequently, 24 (61.5\%) out of the 39 referred patients required additional care $(p<0.001)$. For further general and medical-related background data and periodontal status, please see (Tables 2 and 3). Eighty-eight of the 170 patients had systolic BP beyond the cut-off level.

\section{Clinical periodontal status and number of teeth}

The correlations between the number of pockets with depth of $\geq 4 \mathrm{~mm}$, mean depth $\geq 4 \mathrm{~mm}$ and total $\mathrm{mm}$ pocket depth $\geq 4 \mathrm{~mm}$ were significant $(p<0.001)$. These clinical periodontal status parameters are presented below as data of the number of pockets with depth of $\geq 4 \mathrm{~mm}$.

When all subjects had been analyzed, we found no significant correlations between the number of teeth or the clinical periodontal status and diastolic BP. Three out of four subjects with diastolic BP above the cut-off level $(90 \mathrm{~mm} \mathrm{Hg}$; $85 \mathrm{~mm} \mathrm{Hg}$ for patients with diagnosed DM) had pockets with a depth of $\geq 4 \mathrm{~mm}$, and 14 of the 31 subjects (45.2\%) with diastolic BP above the cut-off level had $\geq 3$ pockets with a depth of $\geq 4 \mathrm{~mm}$. Please see (Table 4 ) for correlations between blood pressure, plasma glucose (PG) and periodontal status.

There were significant correlations between the number of teeth and systolic BP $(p=0.015)$ as well as medication to alleviate CVD ( $p=0.005$ and non-parametric correlation $p<0.001$ ), but no correlation was found between the number of teeth and clinical periodontal status. The correlation between plasma glucose and clinical periodontal status displayed no significance, but $57.1 \%$ of those subjects who exhibited plasma glucose above the cut-off level and who were not on medication for DM had $\geq 3$ pockets with a depth of $\geq 4 \mathrm{~mm}$.

\section{Radiographic periodontal status}

In 16 cases (9.4\%), it was not at all possible to measure the marginal alveolar bone loss on $x$-ray owing to their being edentulous, having small dentitions or a total lack of reference points on $x$-rays: among middle-aged subjects $3.3 \%$ and among elderly subjects $16.3 \%$ fell into this category. The mean for missing data was $20.3 \%$ of the 154 cases under study; among middle-aged subjects the mean was $10.8 \%$ and among elderly subjects, the mean for missing data was $32.8 \%$.

There was no significant correlation between plasma glucose and radiographic periodontal status, but all subjects 
Friman et al. Cardiovascular System 2013,

Table 3. Periodontal status.

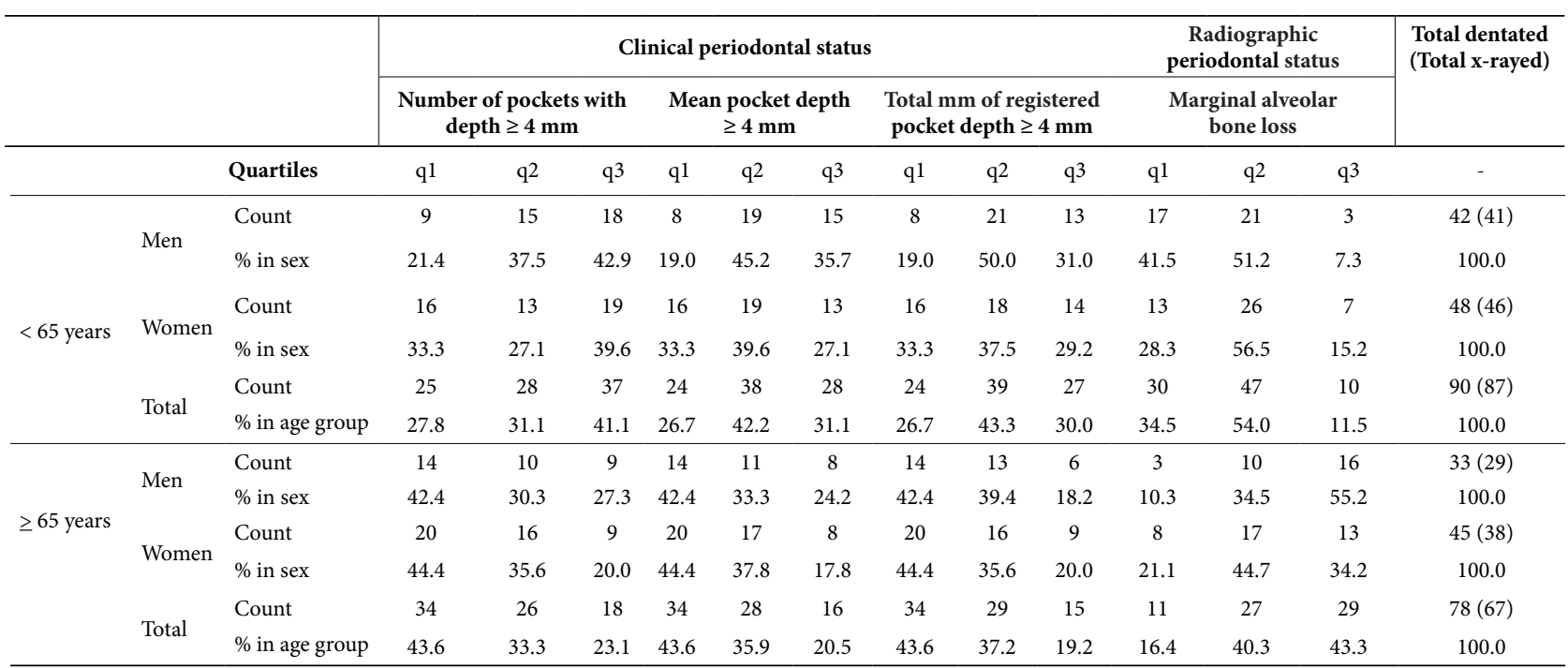

Table 4. Correlation between blood pressure, plasma glucose and periodontal status.

\begin{tabular}{|c|c|c|c|c|c|c|c|}
\hline & Quartiles & $\begin{array}{c}\text { Diastolic BP } \\
<90(<85)\end{array}$ & $\begin{array}{c}\text { Diastolic BP } \\
\geq 90(85)\end{array}$ & $\begin{array}{c}\text { Systolic BP } \\
<140\end{array}$ & $\begin{array}{c}\text { Systolic BP } \\
\geq 140\end{array}$ & $\begin{array}{c}\text { PG below cut-off } \\
\text { level (non- DM } \\
\text { medication) }\end{array}$ & $\begin{array}{c}\text { PG beyond cut-off } \\
\text { level (non- DM } \\
\text { medication) }\end{array}$ \\
\hline \multirow[t]{4}{*}{ Number of teeth } & $\leq 20$ teeth & 48 & 9 & 20 & 37 & $54(55)$ & $3(2)$ \\
\hline & $\%$ in $\mathrm{BP} \& \mathrm{PG}$ group & 34.5 & 29.0 & 24.4 & 42.0 & $33.8(33.7)$ & $30.0(28.6)$ \\
\hline & $>20$ teeth & 91 & 22 & 62 & 51 & $106(108)$ & $7(5)$ \\
\hline & $\%$ in $\mathrm{BP} \& \mathrm{PG}$ group & 65.5 & 71 & 75.6 & 58.0 & $66.3(66.3)$ & $70.0(71.4)$ \\
\hline \multirow[t]{6}{*}{ Number of pockets $\geq 4 \mathrm{~mm}$ with $P D$ of $\geq 4 \mathrm{~mm}$} & $\mathrm{q} 1$ & 51 & 8 & 27 & 32 & $54(57)$ & $5(2)$ \\
\hline & $\%$ in $\mathrm{BP} \& \mathrm{PG}$ group & 37.2 & 25.8 & 32.9 & 37.2 & $34.2(35.4)$ & $50.0(28.6)$ \\
\hline & $\mathrm{q} 2$ & 45 & 9 & 22 & 32 & $53(53)$ & $1(1)$ \\
\hline & $\%$ in $\mathrm{BP} \& \mathrm{PG}$ group & 32.8 & 29.0 & 26.8 & 37.2 & $33.5(32.9)$ & $10.0(14.3)$ \\
\hline & q3 & 41 & 14 & 33 & 22 & $51(51)$ & $4(4)$ \\
\hline & $\%$ in $\mathrm{BP} \& \mathrm{PG}$ group & 29.9 & 45.2 & 40.2 & 25.6 & $32.3(31.7)$ & $40.0(57.1)$ \\
\hline \multirow[t]{6}{*}{ Mean pocket depth $\geq 4 \mathrm{~mm}$} & $\mathrm{q} 1$ & 50 & 8 & 27 & 31 & $54(56)$ & $4(2)$ \\
\hline & $\%$ in BP \& PG group & 36.5 & 25.8 & 32.9 & 36.0 & $34.2(34.8)$ & $40.0(28.6)$ \\
\hline & q2 & 55 & 11 & 31 & 35 & $63(64)$ & $3(2)$ \\
\hline & $\%$ in $\mathrm{BP} \& \mathrm{PG}$ group & 40.1 & 35.5 & 37.8 & 40.7 & $39.9(39.8)$ & $30.0(28.6)$ \\
\hline & q3 & 32 & 12 & 24 & 20 & $41(41)$ & $3(3)$ \\
\hline & $\%$ in BP \& PG group & 23.4 & 38.7 & 29.3 & 23.3 & $25.9(25.5)$ & $30.0(42.9)$ \\
\hline \multirow[t]{6}{*}{ Total $\mathrm{mm}$ of registered PD of $\geq 4 \mathrm{~mm}$} & $\mathrm{q} 1$ & 50 & 8 & 27 & 31 & $54(56)$ & $4(2)$ \\
\hline & $\%$ in BP \& PG group & 36.5 & 25.8 & 32.9 & 36.0 & $34.2(34.8)$ & $40.0(28.6)$ \\
\hline & q2 & 54 & 14 & 29 & 39 & $65(66)$ & $3(2)$ \\
\hline & $\%$ in $\mathrm{BP} \& \mathrm{PG}$ group & 39.4 & 45.2 & 35.4 & 45.3 & $41.1(41.0)$ & $30.0(28.6)$ \\
\hline & q3 & 33 & 9 & 26 & 16 & $39(39)$ & $3(3)$ \\
\hline & $\%$ in $\mathrm{BP} \& \mathrm{PG}$ group & 24.1 & 29.0 & 31.7 & 18.6 & $24.7(24.2)$ & $30.0(42.9)$ \\
\hline \multirow[t]{6}{*}{ Marginal alveolar bone loss } & $\mathrm{q} 1$ & 35 & 6 & 25 & 16 & $41(41)$ & $0(0)$ \\
\hline & $\%$ in $\mathrm{BP} \& \mathrm{PG}$ group & 27.8 & 21.4 & 31.6 & 21.3 & $28.5(27.9)$ & $0(0)$ \\
\hline & q2 & 62 & 12 & 42 & 32 & $69(71)$ & $5(3)$ \\
\hline & $\%$ in $\mathrm{BP} \& \mathrm{PG}$ group & 49.2 & 42.9 & 53.2 & 42.7 & $47.9(48.3)$ & $50.0(42.9)$ \\
\hline & q3 & 29 & 10 & 12 & 27 & $34(35)$ & $5(4)$ \\
\hline & $\%$ in $\mathrm{BP} \& \mathrm{PG}$ group & 23.0 & 35.7 & 15.2 & 36.0 & $23.6(23.8)$ & $50.0(57.1)$ \\
\hline
\end{tabular}

who displayed plasma glucose above the cut-off level exhibited marginal alveolar bone loss $\geq 2 \mathrm{~mm}$, and $57.1 \%$ of the members of this group who were not on medications for DM had $\geq 3.4 \mathrm{~mm}$.

One hundred thirteen of the 154 dental patients (73.4\%) had radiographic marginal alveolar bone loss of $\geq 2 \mathrm{~mm}$ 


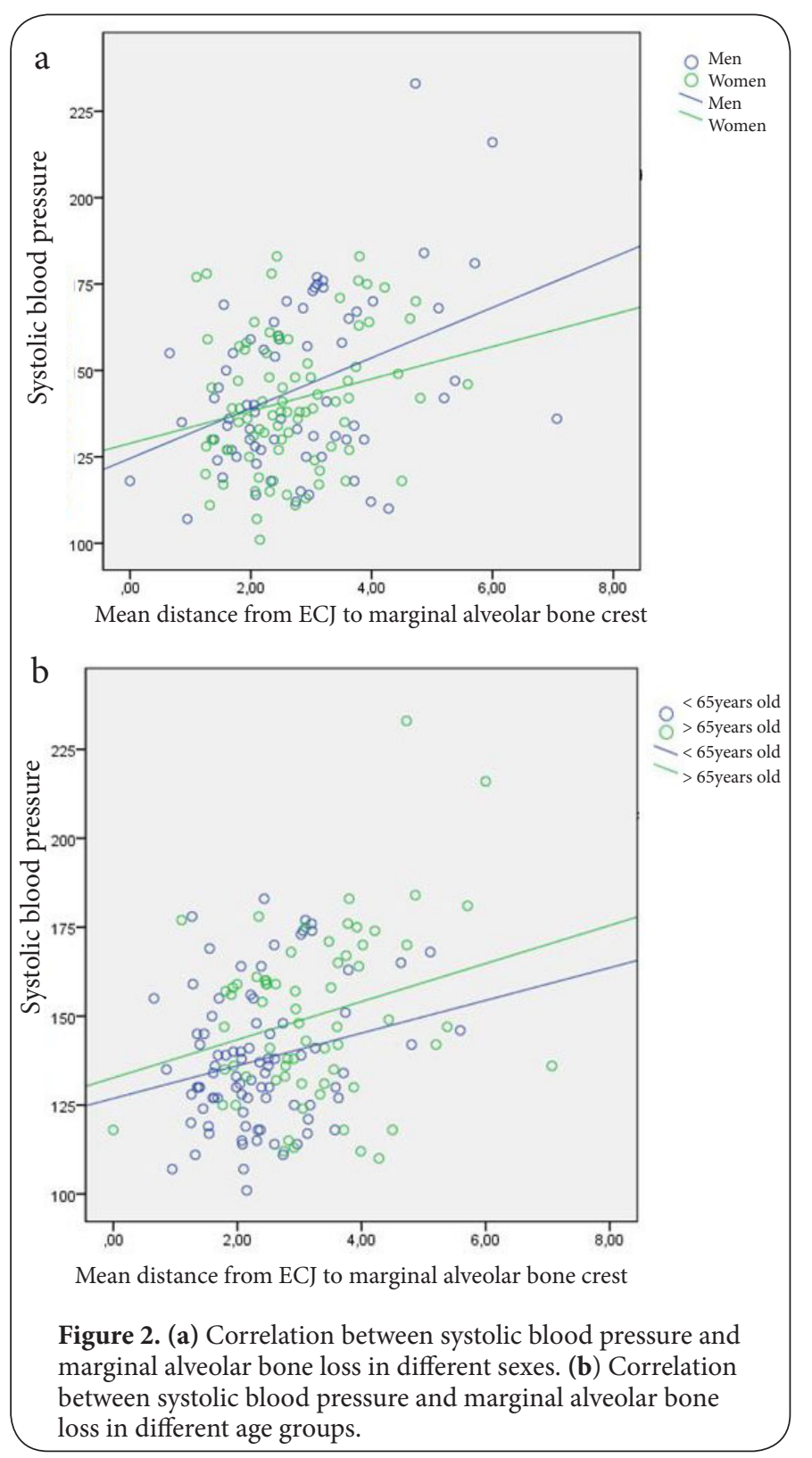

according to the distribution in (Table 3). The mean bone loss of middle-aged subjects was $2.4 \mathrm{~mm}$ (SD 0.9) and in elderly subjects $3.2 \mathrm{~mm}$ (SD 1.2).

In analyzing all patients, no significant correlations were discovered between marginal alveolar bone loss and diastolic BP. Four of five subjects with diastolic BP above the cut-off value showed marginal alveolar bone loss of $\geq 2 \mathrm{~mm}$. Of these 113 with $\geq 2 \mathrm{~mm}, 22$ (19.5\%) had screened diastolic BP above the cut-off value, as compared with six patients (14.6\%) of 41 with a bone loss of $<2 \mathrm{~mm}$. There was no correlation between marginal alveolar bone loss $(p=0.07)$ and taking medication to alleviate CVD.

However, there was both a significant correlation $(p<0.001)$ and a significant non-parametric correlation $(p=0.001)$ between systolic BP and marginal alveolar bone loss. Twenty-seven patients out of a group of 39 (69.2\%) with a bone loss of $\geq 3.4 \mathrm{~mm}$ showed systolic BP $>140 \mathrm{~mm} \mathrm{Hg}$. The correlation was stronger for men $(p=0.001)$ than for women $(p=0.038)$ and there was also a significant nonparametric correlation ( $p=0.008$ and $p=0.049$, respectively) (Figure 2a). Furthermore, significant correlations for middleaged $(p=0.039)$ and elderly $(p=0.029)$ subjects were also discovered (Figure 2b). After controlling for age and sex, significant correlations between systolic BP and marginal alveolar bone loss remained among middle-aged men $(p=0.036)$, while no such correlations were found among women.

Among elderly women, there was a significant correlation between marginal alveolar bone loss and clinical periodontal status ( $p=0.014$ ), while a bone loss of $\geq 2 \mathrm{~mm}$ was less frequent among non-smokers than among smokers.

\section{Age}

An analysis of all patients showed significant correlations between age and medication for CVD ( $p<0.001)$, diastolic BP $(p=0.009)$, systolic BP $(p<0.001)$, marginal alveolar bone loss $(p<0.001)$, missing radiographic data $(p<0.001)$ and clinical periodontal status $(p=0.002)$. There were significant correlations between age and clinical periodontal status among non-smokers $(p=0.016)$ and men $(p=0.007)$, whereas no such correlations were discovered among smokers and women.

\section{Discussion}

\section{Main findings}

We often found undiagnosed high BP and high plasma glucose values in our 170 subjects. Thirty-nine patients with high values were referred, with 24 of them requiring further care ( $14.1 \%$ of all participants).

No significant correlations between plasma glucose and periodontal status were found. Among elderly subjects, there was a significant correlation between marginal alveolar bone loss and high systolic BP.

High BP, a global problem, was noted in $26.4 \%$ of the adult population in 2000 [16], with ischaemic heart disease and cerebrovascular disease being the leading causes of death [17]. In this study, we found that registered BP was correlated to radiographic marginal alveolar bone loss. Male subjects 40-65 years of age evidenced the strongest such correlation, as did subjects of both genders aged 65 and over.

\section{Incidental findings}

Periodontitis in the elderly is not easily confirmed as affected teeth may already have been extracted, because of a perceived need for removal or the previous more technical approach towards dentistry [18]. In this study, we noticed incidentally that radiographic marginal alveolar bone loss 
was present more often than clinical periodontal status, such as BOP linked to pocket depth of $\geq 4 \mathrm{~mm}$, probably thanks to the individualized prophylactic care programs used in the clinic concerned. A pocket depth of $\geq 4 \mathrm{~mm}$ may be a sign of active periodontal disease, while radiographic bone loss is a clear sign of previous periodontal disease.

In the present study, we also incidentally observed that the number of surfaces on which it was impossible to measure marginal alveolar bone loss on $\mathrm{x}$-rays was larger among the oldest patient group. Elderly tend to have a lot of dental restorations [19] that complicate the measurement on bitewing $x$-rays owing to obscured CEJ.

Contemporary Swedish elderly tend to increasingly keep their natural teeth [20]. The importance of medical screening for oral health was highlighted in a study in which the authors [21] concluded that the metabolic syndrome and presence of markers for inflammation, in addition to traditional risk factors for tooth loss, represented threats to maintaining natural teeth in elderly populations. Relevant current data also support the existence of a relationship between metabolic disturbances and periodontitis [22].

\section{Strengths and limitations}

The strength of this investigation is that it was conducted at an ordinary public general dental practice by standard oral health professionals whose mission was to identify patients at risk of CVD and DM. Today, several wrist devices have been validated using the British Hypertension Society protocol; however, validated upper arm devices are still preferred over wrist devices [23] and should, therefore, be recommended for screening activities and control measurements. A digital automatic sphygmomanometer generates values algorithmically based on a single registration. Physiologically, the mean ambulatory monitored BP value is more realistic and has better prognostic value in making diagnostic assessments [24], but is less suitable in a screening situation. The results also show that although an ordinary glucometer made for monitoring concentrations of blood glucose at home was used, a correlation with medical health care of $40.0 \%$ was achieved. A limitation of our study is that it was performed in one dental setting alone; other similar clinical research needs to be performed before the results may be considered transferable to all dental environments.

Another limitation is that we made the assumption that patients would feel calm enough to achieve a relevant digital $\mathrm{BP}$ registration after a five-minute break. This was not the case, as 88 of 170 patients (51.8\%) patients showed systolic BP above the cut-off value of $140 \mathrm{~mm} \mathrm{Hg}$. These results were probably attributable to "white coat hypertension". Studies have shown that patients with high BP readings at a first appointment with a new physician show a mean fall of $15 / 7 \mathrm{~mm} \mathrm{Hg}$ in systolic BP and diastolic BP by their third appointment. Some patients do not reach stable BP values until their sixth appointment $[\mathbf{2 5}, \mathbf{2 6}]$. Dental fear and phobia tend to complicate medical screening in dental settings, but the benefits of medical screening linked to the dental health system, with its annual recall program, may compensate for these disadvantages.

\section{Implications of this study}

Our findings indicate the possibility of identifying risk patients among men and elderly by examining radiographic marginal alveolar bone loss with the help of routine $\mathrm{x}$-rays and by performing medical screenings by measuring BP. However, this requires the establishment of good routines for both the screening procedures and $\mathrm{x}$-ray activities in dental settings. Another issue is whether dental professionals should be involved in the follow-up treatment of hypertension, or alternatively, merely collaborate closely with primary care services in identifying patients at risk.

The absence of a significant correlation between plasma glucose and periodontal status in this study may be attributable to the limited population sample screened or the extended targeted periodontal prophylaxis received by patients with diabetes.

Syrjänen [27] discovered that severe chronic dental infection in young and middle-aged men seems to be strongly associated with stroke (cerebral infarction), a finding that stresses the importance of giving men who evidence markers of periodontal disease extended periodontal prophylaxis. According to our study findings, this also seems relevant for elderly patients in the same situation.

In the absence of a definitive causality, our level of knowledge does not yet enable us to call periodontal status a predictive factor for cardiovascular disease or diabetes mellitus. A statistical limitation also occurs when many statistical associations tested are omitted. In such instances, error rates may soar dramatically, thereby increasing the risk of reaching erroneous conclusions. However, the data of our study might be used to propose a description of cardiovascular parameters and plasma glucose concentrations in groups with affected periodontal status. Our findings suggest a need for additional studies with larger population samples.

Among Swedes aged 50 and above, $81.6 \%$ of this population reported having seen a dentist within the preceding year in 2007 [28]. The continuity of providing ongoing dental services presents an opportunity to identify both oral and general risk factors and points out the benefit of medical screening in dental settings which is why such screening activity has recently been introduced to dentistry and is the subject of research because of its positive results [29-33,8,9,34-37].

\section{Conclusions}

In our study, the correlation between oral health care and medical health care registrations based on blood pressure and plasma glucose indicates that it may be appropriate for dental professionals to perform opportunistic medical screening and refer risk patients to the medical care system 
Friman et al. Cardiovascular System 2013,

before complications occur. In order to identify medical risk patients in dental settings on the basis of high blood pressure, a suggestion may be to examine middle-aged men and elderly patients of both sexes who exhibit radiographic markers for marginal alveolar bone loss.

\section{Abbreviations \\ DM: Diabetes mellitus \\ CVD: Cardiovascular disease \\ BP: Blood pressure \\ BMI: Body mass index \\ BOP: Bleeding on probing \\ CEJ: Cemento-enamel-junction}

Competing interests

The authors declare that they have no competing interests.

\section{Authors' contributions}

GF was principal investigator responsible for planning, design and analysis and wrote the manuscript. IW and GN were involved in planning, design and analysis and drafted the revised manuscript. $\mathrm{MH}$ was involved in planning and design and revised the manuscript. All authors have read and approved the final manuscript.

\section{Acknowledgement and funding}

The authors thank Elisabeth Berg, who performed the statistical analysis, as well as Linda Schenck and Gunilla Ramell who performed the English language editing. This study was supported by the R \& D County Council of Värmland, Sweden, and by Svenska Tandläkares Inköpsförenings Stiftelse för Forskning och Studier, Sweden.

\section{Publication history}

Editor: Felipe A.Martinez, Cordoba National University, Argentina. Received: 23-Feb-2013 Revised: 20-Mar-2013

Accepted: 18-May-2013 Published: 18-Jun -2013

\section{References}

1. 2003 European Society of Hypertension-European Society of Cardiology guidelines for the management of arterial hypertension. J Hypertens 2003, 21:1011-53. | Article | PubMed

2. Bahekar AA, Singh S, Saha S, Molnar J and Arora R: The prevalence and incidence of coronary heart disease is significantly increased in periodontitis: a meta-analysis. Am Heart J 2007, 154:830-7. | Article | PubMed

3. Buhlin K, Hultin M, Norderyd O, Persson L, Pockley AG, Rabe P, Klinge B and Gustafsson A: Risk factors for atherosclerosis in cases with severe periodontitis. J Clin Periodontol 2009, 36:541-9. | Article | PubMed

4. Tonetti MS, D'Aiuto F, Nibali L, Donald A, Storry C, Parkar M, Suvan J, Hingorani $A D$, Vallance $P$ and Deanfield J: Treatment of periodontitis and endothelial function. N Engl J Med 2007, 356:911-20. | Article | PubMed

5. Buhlin K, Hultin M, Norderyd O, Persson L, Pockley AG, Pussinen PJ, Rabe $P$, Klinge $B$ and Gustafsson A: Periodontal treatment influences risk markers for atherosclerosis in patients with severe periodontitis. Atherosclerosis 2009, 206:518-22. | Article | PubMed

6. Kaur G, Holtfreter B, Rathmann W, Schwahn C, Wallaschofski H, Schipf S, Nauck $\mathrm{M}$ and Kocher T: Association between type 1 and type $\mathbf{2}$ diabetes with periodontal disease and tooth loss. J Clin Periodontol 2009, 36:76574. | Article | PubMed

7. Choi YH, McKeown RE, Mayer-Davis EJ, Liese AD, Song KB and Merchant AT: Association between periodontitis and impaired fasting glucose and diabetes. Diabetes Care 2011, 34:381-6. | Article | PubMed Abstract | PubMed Full Text

8. Greenberg BL, Glick M, Frantsve-Hawley J and Kantor ML: Dentists' attitudes toward chairside screening for medical conditions. J Am Dent Assoc 2010, 141:52-62. | Article | PubMed

9. Engstrom S, Berne C, Gahnberg L and Svardsudd K: Efficacy of screening for high blood pressure in dental health care. BMC Public Health 2011, 11:194. | Article | PubMed Abstract | PubMed Full Text

10. Shetty S, Kohad R, Yeltiwar R and Shetty K: Gingival blood glucose estimation with reagent test strips: a method to detect diabetes in a periodontal population. J Periodontol 2011, 82:1548-55. | Article | PubMed

11. Thulin T: The importance of knowing the sources of error in measuring blood pressure. Läkartidningen 2004, 14:1284-1289 (in Swedish).

12. Batki AD, Nayyar P, Holder R, Thomason HL, Thorpe GHG: Roche AccuChek Compact blood glucose meter with the new $1.5 \mu \mathrm{L}$ test strip. Medicines and Healthcare products Regulatory Agency UK 2004, MHRA Evaluation Report MHRA 03145: January 2004.

13. Feig DS, Palda VA and Lipscombe L: Screening for type 2 diabetes mellitus to prevent vascular complications: updated recommendations from the Canadian Task Force on Preventive Health Care. CMAJ 2005, 172:177-80. | Article | PubMed Abstract | PubMed Full Text

14. Ramfjord SP: The Periodontal Disease Index (PDI). J Periodontol 1967, 38:Suppl:602-10. | Article | PubMed

15. Hausmann $\mathrm{E}$, Allen $\mathrm{K}$ and Clerehugh $\mathrm{V}$ : What alveolar crest level on a bite-wing radiograph represents bone loss? I Periodontol 1991, 62:5702. | Article | PubMed

16. Kearney PM, Whelton M, Reynolds K, Muntner P, Whelton PK and He $\mathrm{J}$ : Global burden of hypertension: analysis of worldwide data. Lancet 2005, 365:217-23. | Article | PubMed

17. Mathers $C D$, Boerma $T$ and Ma Fat $D$ : Global and regional causes of death. Br Med Bull 2009, 92:7-32. I Article I PubMed

18. Baelum V, van Palenstein Helderman W, Hugoson A, Yee R and Fejerskov $O: A$ global perspective on changes in the burden of caries and periodontitis: implications for dentistry. J Oral Rehabil 2007, 34:872906; discussion 940. | Article | PubMed

19. Hugoson A, Koch G, Gothberg C, Helkimo AN, Lundin SA, Norderyd O, Sjodin B and Sondell K: Oral health of individuals aged 3-80 years in Jonkoping, Sweden during 30 years (1973-2003). I. Review of findings on dental care habits and knowledge of oral health. Swed Dent J 2005 , 29:125-38. | Article | PubMed

20. Steen B: [The elderly yesterday, today and tomorrow. Aspects of cohort differences and prevention of the manifestations of aging]. Lakartidningen 2001, 98:545-50. I PubMed

21. Holmlund A, Hulthe $J$ and Lind L: Tooth loss is related to the presence of metabolic syndrome and inflammation in elderly subjects: a prospective study of the vasculature in Uppsala seniors (PIVUS). Oral Health Prev Dent 2007, 5:125-30. | PubMed

22. Benguigui C, Bongard V, Ruidavets JB, Chamontin B, Sixou M, Ferrieres J and Amar J: Metabolic syndrome, insulin resistance, and periodontitis: a cross-sectional study in a middle-aged French population. $J$ Clin Periodontol 2010, 37:601-8. I Article | PubMed

23. Ghuman N, Campbell P and White WB: Role of ambulatory and home blood pressure recording in clinical practice. Curr Cardiol Rep 2009, 11:414-21. | Article | PubMed Abstract | PubMed Full Text

24. Fagard RH, Van Den Broeke $C$ and De Cort P: Prognostic significance of blood pressure measured in the office, at home and during ambulatory monitoring in older patients in general practice. J Hum Hypertens 2005, 19:801-7. | Article | PubMed

25. Watson RD, Lumb R, Young MA, Stallard TJ, Davies P and Littler WA: Variation in cuff blood pressure in untreated outpatients with mild hypertension--implications for initiating antihypertensive treatment. $J$ Hypertens 1987, 5:207-11. | Article | PubMed

26. Cohen DL and Townsend RR: How significant is white coat hypertension? J Clin Hypertens (Greenwich) 2010, 12:625-6. | Article | PubMed

27. Syrjanen J, Peltola J, Valtonen V, livanainen M, Kaste $M$ and Huttunen JK: Dental infections in association with cerebral infarction in young and 
Friman et al. Cardiovascular System 2013,

middle-aged men. J Intern Med 1989, 225:179-84. | Article | PubMed

28. Listl S, Moran V, Maurer J and Faggion CM, Jr.: Dental service utilization by Europeans aged 50 plus. Community Dent Oral Epidemiol 2012, 40:164-74. | Article | PubMed

29. Glick M: Screening for traditional risk factors for cardiovascular disease: a review for oral health care providers. J Am Dent Assoc 2002, 133:291300. | Article | PubMed

30. Glick $M$ and Greenberg BL: The potential role of dentists in identifying patients' risk of experiencing coronary heart disease events. J Am Dent Assoc 2005, 136:1541-6. | Article | PubMed

31. Greenberg BL, Glick M, Goodchild J, Duda PW, Conte NR and Conte M: Screening for cardiovascular risk factors in a dental setting. J Am Dent Assoc 2007, 138:798-804. | Article | PubMed

32. Nicolas E, Lassauzay C, Pickering G, Croze J and Hennequin M: Needs in screening cardiovascular parameters during dental care in the elderly. Aging Clin Exp Res 2008, 20:272-6. | Article | PubMed

33. Jontell $M$ and Glick $M$ : Oral health care professionals' identification of cardiovascular disease risk among patients in private dental offices in Sweden. J Am Dent Assoc 2009, 140:1385-91. | Article | PubMed

34. Lalla E, Kunzel C, Burkett S, Cheng B and Lamster IB: Identification of unrecognized diabetes and pre-diabetes in a dental setting. I Dent Res 2011, 90:855-60. | Article | PubMed

35. Lamster IB and Eaves K: A model for dental practice in the 21st century. Am J Public Health 2011, 101:1825-30. | Article | PubMed

36. Greenberg BL, Kantor ML, Jiang SS and Glick M: Patients' attitudes toward screening for medical conditions in a dental setting. J Public Health Dent 2012, 72:28-35. | Article | PubMed

37. Strauss SM, Alfano MC, Shelley D and Fulmer T: Identifying unaddressed systemic health conditions at dental visits: patients who visited dental practices but not general health care providers in 2008. Am J Public Health 2012, 102:253-5. | Article | PubMed

\section{Citation:}

Friman G, Wårdh I, Nilsson G and Hultin M: Identifying patients in dental settings at risk of cardiovascular disease and diabetes. Cardiovascular System 2013, 1:5. http://dx.doi.org/10.7243/2052-4358-1-5 